\title{
Alteraciones morfológicas en pulmón por la influenza A H1N1/v09 en autopsias, Colombia, 2009
}

\author{
Jorge Rivera ${ }^{1}$, Ladys Sarmiento², Edgar Parra ${ }^{3}$, Gabriel Toro ${ }^{3}$, Marcela Neira³ ${ }^{3}$ Jairo Méndez4,
} Juliana Barbosa ${ }^{4}$, María Leonor Caldas ${ }^{2}$

1 Joven investigador, Grupo de Morfología Celular, Instituto Nacional de Salud, Bogotá, D.C., Colombia

2 Grupo de Morfología Celular, Subdirección de Investigación, Instituto Nacional de Salud, Bogotá, D.C., Colombia

${ }^{3}$ Grupo de Patología, Subdirección de la Red Nacional de Laboratorios, Instituto Nacional de Salud, Bogotá, D.C., Colombia.

${ }^{4}$ Grupo de Virología, Subdirección de la Red Nacional de Laboratorios, Instituto Nacional de Salud, Bogotá, D.C., Colombia

Introducción. La influenza es una infección respiratoria aguda que se presenta de forma estacional y pandémica. En el 2009, la Organización Mundial de Salud (OMS) declaró una pandemia por influenza de tipo A en la que se reportaron en Colombia 3.876 casos de infección, de los cuales 239 fallecieron. Objetivo. Describir los cambios morfológicos asociados a la infección por el virus A H1N1/v09 en tejido pulmonar de autopsias de la pandemia de 2009 en Colombia.

Materiales y métodos. Se estudiaron 75 casos con diagnóstico por RT-PCR para el virus A H1N1/v09, de los cuales, 20 fueron seleccionados para el estudio morfológico mediante microscopía convencional de luz, microscopía óptica de alta resolución y electrónica de transmisión e inmunohistoquímica.

Resultados. De los 75 casos estudiados, $83 \%$ presentaron pneumonitis viral y $17 \%$ alveolitis. Se observaron complicaciones por hemorragia intraalveolar (66 \%) y edema (89\%), daño alveolar difuso (2\%) e infección bacteriana concomitante (32\%).

Algunos de los cambios morfológicos observados fueron: destrucción del epitelio alveolary el instersticio, edema, macrófagos con citoplasma vacuolado e infiltración de leucocitos polimorfonucleares en la luz alveolar y el intersticio; vacuolización citoplásmica en neumocitos de tipo I y cuerpos electrodensos en restos celulares en la luz alveolar; inmunorreacción de antígenos virales en el epitelio bronquiolar y en células del infiltrado alveolar.

Conclusión. El porcentaje bajo de infección bacteriana concomitante observado en los casos de influenza A H1N1/ v09 en este estudio, es una característica sobresaliente que sugiere que el resultado fatal de la infección, probablemente no esté asociado a una enfermedad bacteriana secundaria, como se ha sugerido en reportes previos. Es probable que las lesiones observadas se puedan atribuir al daño tisular en la respuesta inflamatoria celular y humoral asociada a la infiltración por células poliformonucleares y macrófagos en el intersticio y la luz alveolares, como también por la lesión viral.

Palabras clave: subtipo H1N1 del virus de la influenza A, infecciones bacterianas, pandemias, microscopía, reacción en cadena de la polimerasa de transcriptasa inversa.

\section{Morphological changes in lung tissue of victims associated with the 2009 A H1N1/v09 influenza pandemic in Colombia}

Introduction. Influenza is an acute respiratory infection that may be seasonal or pandemic. In 2009 The World Health Organization (WHO) declared an influenza pandemia; 3,876 cases and 239 deaths were reported in Colombia.

\footnotetext{
Contribución de los autores:

Jorge Rivera: procesamiento de muestras para el estudio morfológico mediante microscopía convencional, microscopía electrónica de transmisión e inmunohistoquímica y escritura del manuscrito.

Ladys Sarmiento: obtención de cortes semifinos y finos, estudio mediante microscopía electrónica de transmisión e inmunohistoquímica y revisión del manuscrito.

Edgar Parra: diagnóstico histopatológico mediante microscopía de luz convencional y selección de los 20 casos para el estudio morfológico por microscopía óptica de alta resolución, microscopía electrónica de transmisión e inmunohistoquímica.

Gabriel Toro: diagnóstico histopatológico mediante microscopía convencional de luz.

Marcela Neira: procesamiento de muestras para el estudio morfológico mediante inmunohistoquímica.

Jairo Méndez: procesamiento de muestras mediante RT-PCR en tiempo real, y revisión y análisis del manuscrito.

Juliana Barbosa: procesamiento de muestras mediante RT-PCR en tiempo real.

María Leonor Caldas: estudio ultraestructural mediante microscopía electrónica de transmisión, revisión del manuscrito, planteamiento, seguimiento y ejecución del estudio realizado
} 
Objective. The morphological changes in lung tissues associated with virus infection H1N1/v09 were described from autopsied victims.

Materials and methods. Seventy-five cases were diagnosed by RT-PCR for influenza A H1N1/v09, of which the lungs of 20 were selected for morphological study by light microscopy, optical microscopy, high-resolution transmission electron microscopy and immunohistochemistry.

Results. Of the 75 cases, $83 \%$ had viral pneumonitis and $17 \%$ alveolitis. Complications included intraalveolar hemorrhage (66\%), edema (89\%), diffuse alveolar damage (2\%), and bacterial co-infection $(32 \%)$. Morphological changes were as follows: destruction of the alveolar epithelium and interstitium, edema, macrophages with vacuolated cytoplasm,and infiltration of polymorphonuclear leukocytes in the alveolar lumen and interstitium, vacuolization cytoplasmic type I pneumocytes and electron-dense bodies in cellular debris in the alveolar lumen, and immunoreactivity of viral antigens in bronchiolar epithelial cells and alveolar infiltrate.

Conclusion. The low percentage of bacterial co-infection observed in these cases was a prominent feature, and suggested that the fatal result was probably not associated with secondary bacterial disease (Indicated by previous reports). The tissue lesions were attributed to tissue damage due to viral lesion, as well as the cellular and humoral inflammatory response associated with infiltration by polymorphonucleocytes and macrophages in the interstitium and alveolar lumen.

Key words: influenza A virus, H1N1 subtype; bacterial infections, pandemics, microscopy, reverse transcriptase polymerase chain reaction.

La influenza es una enfermedad respiratoria aguda que se presenta de forma estacional y pandémica; se encuentra entre las enfermedades con mayor carga de pacientes en el mundo (1) y representa uno de los mayores riesgos en salud pública. En 1919 causó cerca de 50 millones de muertes en la pandemia denominada "influenza española", en 1957 y 1968 causó 3 a 6 millones de casos fatales (2-4) y en 2009 la Organización Mundial de la Salud (OMS) declaró la pandemia más reciente

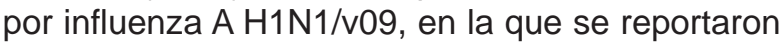
18.172 muertes en el mundo, y en Colombia se confirmaron 239 muertes y 3.876 casos de infección (5).

La influenza es causada por un virus que pertenece a la familia Orthomixoviridae y comprende tres tipos ( $A, B$ y $C)$, cuyas diferencias radican en la base de un antígeno soluble (antígeno S) asociado a la ribonucleoproteína interna del virión. El tipo viral puede diferenciarse a partir de las propiedades biológicas de proyecciones en la superficie de la envoltura, las glucoproteínas hemaglutinina $(H)$ y neuroaminidasa $(N)(6)$, que dan lugar a 15 subtipos para la primera y 9 subtipos para la segunda. Sin embargo, sólo tres subtipos de hemaglutinina $(\mathrm{H} 1$, $\mathrm{H} 2$ y $\mathrm{H} 3$ ) y dos subtipos de neuroaminidasa (N1 y N2) se han establecido en la población humana (7).

\footnotetext{
Correspondencia:

María Leonor Caldas, Grupo de Morfología Celular, Subdirección de Investigación, Instituto Nacional de Salud, Avenida calle 26 № 51-20, Bogotá, D.C., Colombia

Teléfono: (571) 220 7700, extensión 1262; fax: (571) 2200901 mcaldas@ins.gov.co

Recibido: 17/05/11; aceptado:19/05/11
}

La partícula viral es pleomorfa y presenta un tamaño en un rango entre 120 a $150 \mathrm{~nm}$; se caracteriza por poseer una envoltura compuesta por una bicapa lipídica modificada por la adición de proteínas virales (4). A nivel molecular, el genoma está organizado en ocho fragmentos de ARN sencillo de polaridad negativa, cada uno cubierto por una nucleoproteína. Tres de estos fragmentos codifican para las proteínas estructurales principales, la nucleoproteína y las dos glucoproteínas de superficie hemaglutinina y neuroaminidasa; otros tres codifican para las proteínas PB1, PB2 y PA, responsables tanto de la replicación del genoma como de la expresión del ARN mensajero; el fragmento 7 produce las proteínas de matriz asociadas a la envoltura viral M1 y M2, y el fragmento 8 codifica proteínas no estructurales NS1 y NS2 $(4,6)$.

Mediante receptores de ácido siálico localizados en la superficie de las células huésped, el virus infecta el sistema respiratorio, induciendo cambios morfológicos en tráquea, bronquios, bronquiolos y alvéolos pulmonares. En los casos no fatales de la infección, se ven comprometidas, principalmente, las vías respiratorias superiores, incluyéndose la tráquea, mientras que en los casos fatales, el compromiso se presenta en las vías respiratorias bajas, causando neumonitis frecuentemente asociada a neumonía (8).

Los cambios morfológicos inducidos por la infección han sido ampliamente revisados; sin embargo, debido a que no son específicos y propios del virus, es importante que se realicen más estudios sobre descripciones de estos 
cambios, con el fin de contribuir al diagnóstico de la enfermedad (9).

En Colombia no existen reportes de casos o de estudios dirigidos a la descripción de los cambios morfológicos asociados a la infección por el virus respiratorio pandémico $\mathrm{A} \mathrm{H} 1 \mathrm{~N} 1 / \mathrm{v} 09$.

Como una contribución al conocimiento de esta enfermedad, el presente estudio tuvo como objetivo describir los cambios morfológicos asociados a la infección por influenza en las muestras de tejido pulmonar de los pacientes que fallecieron entre mayo y diciembre de 2009, en la pandemia por influenza, mediante técnicas como microscopía convencional de luz, microscopía óptica de alta resolución, microscopía electrónica de transmisión e inmunohistoquímica.

\section{Materiales y métodos}

Muestras y estudio histopatológico. Entre mayo y diciembre de 2009, se procesaron 339 muestras de tejido pulmonar en fresco por reacción en cadena de la polimerasa de transcriptasa inversa, RT-PCR (Reverse Transcriptase Polymerase Chain Reaction), en tiempo real para el diagnóstico de influenza A H1N1/v09 en el Laboratorio de Virología del Instituto Nacional de Salud. Posteriormente, las muestras de tejido fueron fijadas en formol neutro al $10 \%$ e incluidas en bloques de parafina para el estudio por microscopía convencional de luz en el Laboratorio de Patología del Instituto Nacional de Salud.

El estudio histopatológico por examen microscópico rutinario se realizó con la coloración de hematoxilina y eosina de los casos positivos por RT-PCR; de éstos, se seleccionaron 20 casos con muestra representativa de tejido pulmonar (alvéolos y bronquiolos) para el estudio mediante microscopía óptica de alta resolución, microscopía electrónica de transmisión e inmunohistoquímica.

Detección de ARN viral (RT-PCR). Se empleó RT-PCR para la detección de ARN viral en tiempo real, como se describe brevemente a continuación. El tejido fresco conservado en solución salina estéril, se trató con $500 \mu \mathrm{l}$ de solución de lisis (Tris$\mathrm{HCl} 100$ mM, pH 8,5; EDTA 0,5 M; SDS al $10 \%$, proteinasa $\mathrm{K} 25 \mathrm{mg} / \mathrm{ml}$ y 20 unidades de inhibidor de ARNasas) en baño serológico a $56^{\circ} \mathrm{C}$ entre 5 y 10 horas. Posteriormente, se procesaron $140 \mu \mathrm{l}$ del producto lisado con el estuche de extracción de ARN viral QIAamp Viral RNA Mini Kit巴 (Qiagen, Hilden, Germany), siguiendo las instrucciones del fabricante. Finalmente, siguiendo el protocolo establecido por los Centers for Disease Control and Prevention (CDC), en el que se utilizan sondas de tipo Taqman específicas para la detección de virus de influenza $A$ y virus A H1N1/v09, el ARN obtenido se sometió a la reacción de transcripción inversa seguida de reacción en cadena de polimerasa en tiempo real (rRT-PCR) en un solo paso (10). Tanto la reacción como las curvas de amplificación fueron evaluadas en el equipo para tiempo real Step One Plus® (Applied Biosystems).

Microscopía óptica de alta resolución y microscopía electrónica de transmisión. Se procesaron muestras de tejido pulmonar incluido en parafina para el estudio mediante microscopía óptica de alta resolución y microscopía electrónica como se describe a continuación. Al tejido se le eliminó la parafina en xilol a $60^{\circ} \mathrm{C}$ realizando tres cambios de solución e incubando toda la noche a la temperatura indicada. Posteriormente, se hidrató con un gradiente alcohólico con concentraciones descendentes de 100 a $50 \%$; después de fijar en tetraóxido de osmio $\left(\mathrm{OsO}_{4}\right)$ al $1 \%$ por 2 horas y deshidratar del tejido con un gradiente alcohólico con concentraciones ascendentes de 50 a $100 \%$, el tejido fue incluido en resina epón-araldita y se polimerizó por 48 horas a $68^{\circ} \mathrm{C}$.

Del tejido incluido en resina, se tiñeron con azul de toluidina los cortes semifinos de $0,5 \mu \mathrm{m}$ de grosor, para el estudio mediante microscopía óptica de alta resolución. Posteriormente, se obtuvieron cortes ultrafinos de $90 \mathrm{~nm}$ de grosor, los cuales se contrastaron con solución de Reynolds y acetato de uranilo acuoso al $6 \%$, para el estudio mediante microscopía electrónica de transmisión.

Inmunohistoquímica. Para los ensayos de inmunohistoquímica, a los cortes de tejido pulmonar de 3 a $4 \mu \mathrm{m}$ de grosor se les eliminó la parafina en xilol y se rehidrataron en gradiente etanólico. Las preparaciones se sometieron a digestión enzimática con tripsina $(0,8 \mathrm{mg} / \mathrm{ml})$ por 30 minutos a $37^{\circ} \mathrm{C}$ y se incubaron con peróxido de hidrógeno al 0,9\% para bloqueo de la peroxidasa endógena, o con ácido acético glacial al $20 \%$ por 2 minutos a $4{ }^{\circ} \mathrm{C}$ para bloqueo de la fosfatasa alcalina endógena. Posteriormente, el tejido se colocó en solución acuosa de EDTA en dilución 1:20 por 30 minutos.

Después de un bloqueo con suero normal de caballo en dilución 1:20 en PBS por 30 minutos, el tejido se incubó con los siguientes anticuerpos: CD68 para macrófagos (Dako, dilución 1:200), CD3 y CD20 para linfocitos $T$ y $B$, respectivamente 
(Novocastra, dilución lista para uso), y anti-influenza A para antígeno viral (Chemicon, Internacional, dilución 1:800). Todas las incubaciones se hicieron en cámara húmeda por una hora a temperatura ambiente.

Después de un lavado, el tejido se incubó con anticuerpo secundario en dilución 1:300 en PBS por 20 minutos (anti-lgG de cabra con biotina). Posteriormente, se incubó con estreptavidina conjugada a fosfatasa alcalina (Vector Laboratories) por 30 minutos o usando el kit ABC® (Vectastain $A B C$ Kit, Vector Laboratories). Se usaron estuches de revelado para fosfatasa (Dako, Liquid Permanent Red) y diaminobencidina (Zymed). Se hicieron coloraciones de contraste con hematoxilina de Harris.

Se incluyeron controles positivos y negativos en cada prueba de inmunohistoquímica.

\section{Resultados}

De mayo a diciembre de 2009 en los laboratorios de Virología y Patología del Instituto Nacional de Salud, se registraron 339 casos fatales asociados a infección respiratoria aguda, de los cuales, 160 (47\%) presentaban lesiones por neumonía y en 76 se reportó un diagnóstico positivo por RT-PCR en tiempo real para el virus pandémico A H1N1/v09. Los casos con diagnóstico positivo para influenza de tipo A estuvieron en un rango de edad de 7 meses a 61 años y una media de 31 años (cuadro 1).

De los 76 casos positivos para RT-PCR, se excluyeron 23 del estudio morfológico por no poseer una muestra adecuada de tejido; de los 53 restantes, 44 (83\%) presentaron un diagnóstico histopatológico de neumonitis aguda con exudado fibrinoide, y 9 (17\%) presentaron alveolitis aguda necrosante (figura 1, A y B, respectivamente). Como complicaciones, se presentó hemorragia intraalveolar en $66 \%$, edema en $89 \%$, daño alveolar difuso en $2 \%$ y $32 \%$ fueron sugestivos de posible infección bacteriana concomitante. Otros hallazgos histopatológicos importantes de un grupo de casos, se muestran en el cuadro 2.

En la microscopía óptica de alta resolución se encontraron las siguientes alteraciones: necrosis del epitelio bronquiolar, destrucción del epitelio y del intersticio alveolar acompañado de congestión de capilares, formación de hebras de fibrina sobre la pared alveolar y aumento de colágeno, macrófagos con citoplasma vacuolado e infiltración de leucocitos polimorfonucleares en la luz y el intersticio alveolares (figura 1, C y D). En algunas
Cuadro 1. Características de los 76 casos que presentaron PCR positiva para A H1N1/v09

\begin{tabular}{lc}
\hline Características & Valores \\
\hline Hombres, $\mathrm{n} / \mathrm{N}(\%)$ & $36 / 76(47 \%)$ \\
Mujeres, $\mathrm{n} / \mathrm{N}(\%)$ & $40 / 76(53 \%)$ \\
Media de edad* (rango) $^{*}$ & $31(0,5-61)$ \\
Distribución de infección por & \\
edad (años) & \\
$<10$ & $5 / 72(6,6)$ \\
$\geq 10 \mathrm{a}<20$ & $8 / 72(10,5)$ \\
$\geq 20 \mathrm{a}<30$ & $27 / 72(35,5)$ \\
$\geq 30 \mathrm{a}<40$ & $13 / 72(17,1)$ \\
$\geq 40 \mathrm{a}<50$ & $7 / 72(9,2)$ \\
\hline
\end{tabular}

* En cuatros casos no hubo datos de la edad.

células del epitelio alveolar se observaron cambios reactivos, como núcleos alargados.

En el estudio ultraestructural mediante microscopía electrónica se encontró ruptura de membranas citoplásmicas, retículos endoplásmicos dilatados y engrosamiento de membranas basales en células del epitelio alveolar, colágeno y fibroblastos en el intersticio, prominencia de restos celulares y cuerpos electrodensos en la luz alveolar y bronquiolar con necrosis epitelial (figura 2). Se observó frecuentemente edema, vacuolización citoplásmica y cuerpos laminares en el núcleo de neumocitos de tipo I (figura 3), así como un número importante de polimorfonucleares en la luz y el intersticio alveolares. No se observaron partículas virales.

Mediante inmunohistoquímica, se determinó que parte del infiltrado de células en la luz y el intersticio alveolar, consistía de macrófagos y linfocitos $B$ y $T$, con una menor proporción de linfocitos $B$ que de $T$ (proporción 1:20) (figura 4). Observamos inmunorreacción de antígenos virales, principalmente en el citoplasma de células epiteliales del bronquiolo, la cual es menor en células del epitelio alveolar (figura 1F).

\section{Discusión}

Los cambios morfológicos descritos en este estudio concuerdan con las descripciones recientes sobre las alteraciones histopatológicas asociadas a la infección del virus de la influenza en la pandemia de 2009 (11-14), y con los estudios de modelos animales y los reportes de casos de autopsia de pandemias anteriores y de casos de influenza estacional $(8,15,16)$. Entre los cambios morfológicos más importantes, se encuentran la pérdida de la capa epitelial en el bronquiolo, congestión, edema e infiltrado inflamatorio en el intersticio alveolar, 


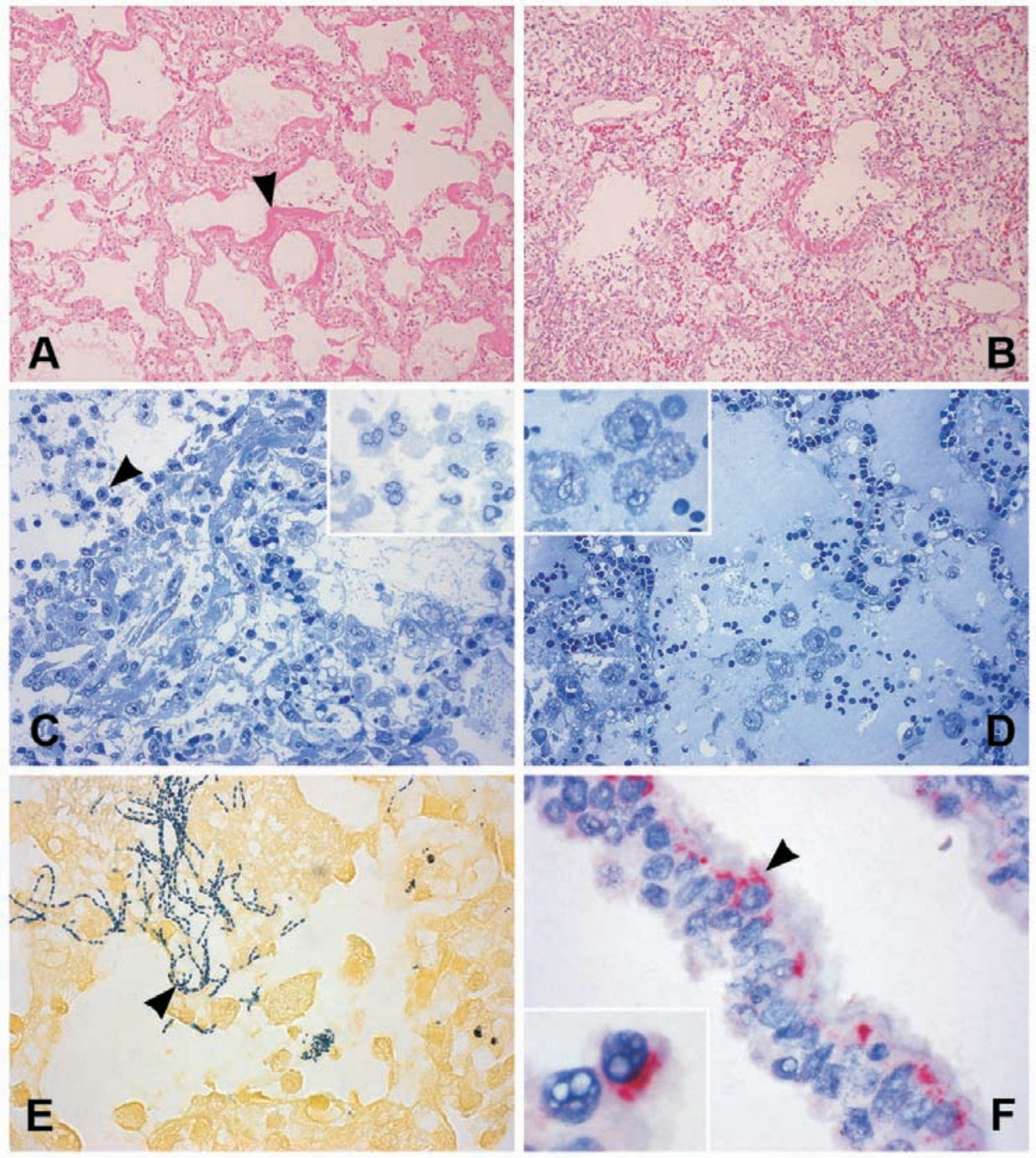

Figura 1. Cambios morfológicos representativos asociados a la infección por virus respiratorio A H1N1/v09. A) Neumonitis aguda exudativa fribrinoide, hebras de fibrina que recubren la pared alveolar (punta de flecha) (40X). B) Alveolitis aguda necrosante con infiltrado inflamatorio notorio (60X). C) Células polimorfonucleares del infiltrado en la luz y el intersticio alveolares (400X, inserto $1.000 X)$. D) Edema y macrófagos con citoplasma vacuolado, localizados en la luz alveolar (400X; inserto, 1.000X). E) Bacterias Gram positivas morfológicamente sugestivas de estreptococos (punta de flecha) (1.000X). F) Células del epitelio bronquiolar con marcación para influenza A H1N1/v09 (punta de flecha) (1.000X), inmunorreacción en citoplasma de células bronquiolares con núcleos vacuolados (inserto, 2.000X).

la formación de membranas hialinas en alvéolos y conductos alveolares, acompañada de edema y hemorragia intraalveolar en un grado variable.

Diferentes estudios señalan que parte de las complicaciones del cuadro histopatológico de la neumonitis por influenza que se presenta en un porcentaje alto de los casos fatales, están asociadas a las infecciones bacterianas secundarias o coincidentes $(8,9,17)$ (figura 1E). Sin embargo, nuestros resultados, con un porcentaje de infección bacteriana concomitante de $32, \%$, no reflejan una asociación directa entre sobreinfección y fatalidad, por lo que es probable que los cambios morfológicos del tejido puedan atribuirse más a un efecto citopático viral que a una infección secundaria, sin descartar daños asociados a una respuesta inflamatoria humoral y celular $(18,19)$; esta última fue más importante, si se tiene en cuenta la mayor cantidad detectada de linfocitos $\mathrm{T}$.

Este estudio y otros estudios recientes, sugieren que esta respuesta inflamatoria puede contribuir en el mecanismo de la lesión pulmonar y, también, sugieren la participación de inmunomoduladores en 
Cuadro 2. Características de los 76 casos que presentaron PCR positiva para A H1N1/v09

\begin{tabular}{|c|c|c|c|c|c|c|}
\hline Edad & Sexo & $\begin{array}{l}\text { Periodo de } \\
\text { infección }^{\star}\end{array}$ & Patología & RT-PCR & IHQ1 & Coinf2 \\
\hline 26 & $\mathrm{~F}$ & 15 & Neumonitis intersticial, traqueobronquitis y linfadenitis reactiva & + & + & ++ \\
\hline SD & $\mathrm{F}$ & SD & Laringotraqueobronquitis necrosante & + & - & +++ \\
\hline 28 & $\mathrm{~F}$ & 8 & Traqueobronquitis necrosante & + & ++ & + \\
\hline 40 & $\mathrm{~F}$ & SD & Traqueítis, neumonía concomitanrte & + & + & - \\
\hline 30 & M & 6 & Traqueobronquitis y bronquiolitis aguda & + & + & - \\
\hline 32 & $\mathrm{~F}$ & 9 & Laringotraqueobronquitis aguda necrosante & + & ++ & + \\
\hline 39 & $\mathrm{~F}$ & 11 & Tráquea normal & + & ++ & \\
\hline 26 & M & 10 & $\begin{array}{l}\text { Neumonía aguda grave en fase de consolidación temprana } \\
\text { indicativa de origen viral }\end{array}$ & + & +++ & - \\
\hline 49 & M & 6 & $\begin{array}{l}\text { Neumonía aguda grave en fase de organización temprana, } \\
\text { traqueítis aguda }\end{array}$ & + & ++ & - \\
\hline 45 & $\mathrm{~F}$ & 8 & Traqueítis aguda leve & + & + & - \\
\hline 23 & $\mathrm{~F}$ & 12 & $\begin{array}{l}\text { Neumonía lobar en fase de hepatización blanca con componente } \\
\text { hemorrágico agudo }\end{array}$ & + & - & + \\
\hline 29 & M & 8 & Traqueobronquitis aguda & + & ++ & \\
\hline 22 & $\mathrm{~F}$ & SD & Neumonía sobreagregada grave & + & + & - \\
\hline 49 & $\mathrm{~F}$ & 10 & Hemorragia pulmonar grave Edema y congestión & + & + & - \\
\hline 14 & M & 7 & Neumonitis difusa aguda con neumonía multifocal sobreagregada & + & + & - \\
\hline 21 & $\mathrm{~F}$ & 18 & $\begin{array}{l}\text { Neumonía bacteriana aguda grave con traqueítis necrosante } \\
\text { y pleuritis fibrinosa }\end{array}$ & + & + & + \\
\hline 54 & $\mathrm{~F}$ & 4 & $\begin{array}{l}\text { Microtrombos de fibrina, edema alveolar generalizado } \\
\text { Traqueobronquitis aguda }\end{array}$ & + & + & - \\
\hline 29 & M & SD & Neumonitis intersticial, traqueobronquitis y linfadenitis reactiva & + & + & - \\
\hline 50 & M & 3 & $\begin{array}{l}\text { Traqueobronquitis aguda necrosante, ronconeumonía con } \\
\text { formación de abscesos. }\end{array}$ & + & ++ & ++ \\
\hline 28 & M & 2 & $\begin{array}{l}\text { Traqueítis aguda grave y necrosante, neumonía aguda en } \\
\text { consolidación temprana }\end{array}$ & + & + & + \\
\hline
\end{tabular}

*Periodo de infección: tiempo en días, entre inicio de síntomas y fallecimiento; SD: sin dato; 'IHQ: inmunohistoquímica para antígeno viral; Coinf²: infección bacteriana concomitante; todos los casos de infección fueron de Gram positivos.

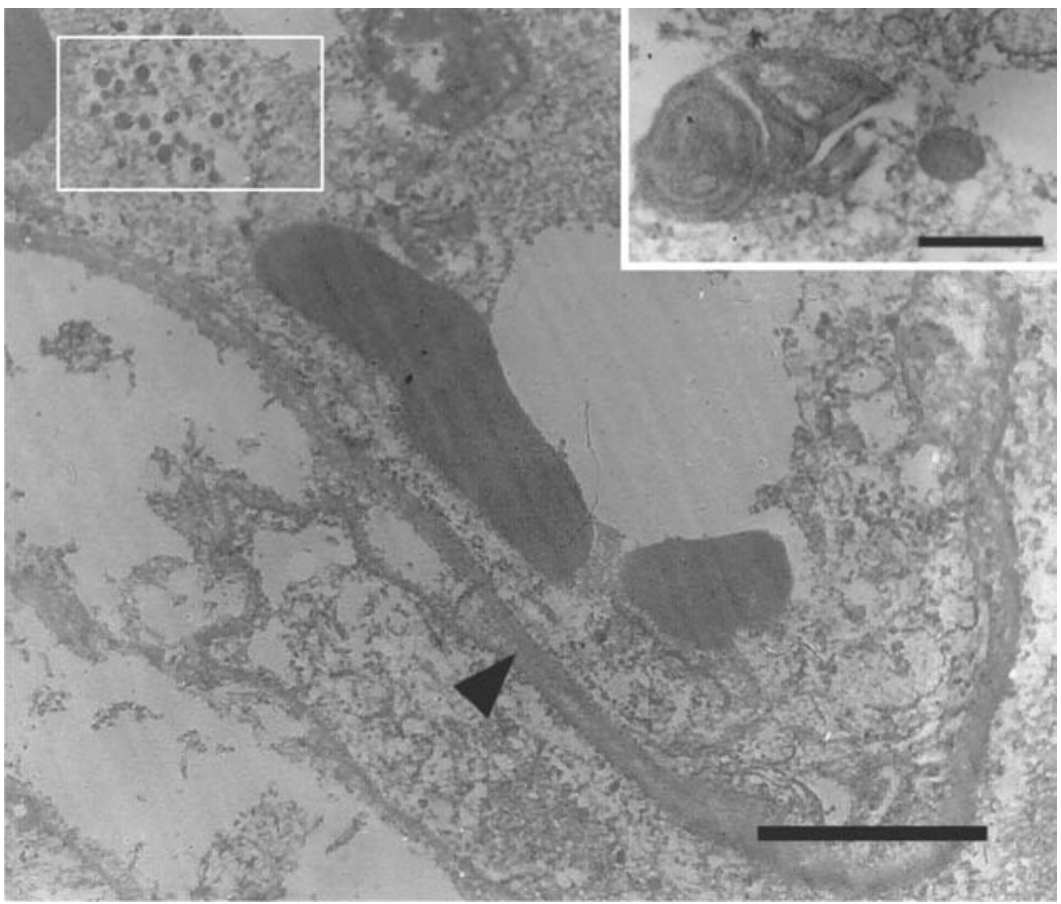

Figura 2. Membrana basal con engrosamientos mínimos (punta de flecha), formación de cuerpos laminares electrodensos en la luz alveolar (recuadro e inserto) y prominencia de restos celulares (barra $=2,5 \mu \mathrm{m}$ y barra del inserto $=0,25 \mu \mathrm{m})$. Micrografía electrónica de tejido pulmonar con infección por virus de influenza A H1N1/v09. 


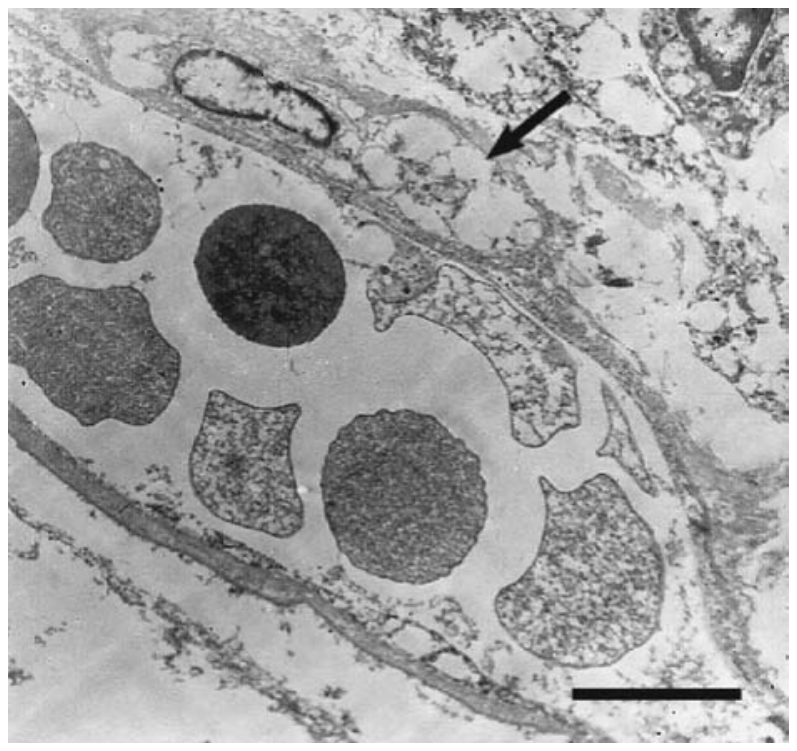

Figura 3. Vénula con paredes medianamente gruesas que contiene gran cantidad de eritrocitos; célula de la pared alveolar con citoplasma vacuolado (flecha); célula del infiltrado en el alvéolo (parte superior derecha) (barra=4 $\mu \mathrm{m}$ ). Micrografía electrónica de tejido pulmonar con infección por virus de influenza A H1N1/v09.

los casos graves y progresivos $(20,21)$. Nicholson, et al. (2003), concuerdan con que el balance entre la replicación viral y la respuesta inmunitaria del huésped determina el resultado de la infección y el daño en el tejido pulmonar; por ejemplo, las cepas de influenza muy virulentas, como la H5N1, poseen la capacidad de resistir los efectos antivirales de las citocinas del huésped (22) y, a su vez, inducen una expresión alta de citocinas asociada a la proliferación de macrófagos. Por lo tanto, es probable que los casos fatales analizados en este estudio, sean el resultado de una pérdida de inhibición de la replicación viral y de un exceso en la expresión de citocinas $(23,24)$.

Por otra parte, las observaciones aquí hechas sobre los cambios morfológicos, han sido confirmadas y asociadas a enfermedades virales en estudios de ultraestructura llevados a cabo en modelos animales. Laproliferación de macrófagos alveolares, el engrosamiento de la barrera de intercambio gaseoso debido al edema en áreas focales del endotelio capilar, y la degeneración y descamación del epitelio alveolar, son alteraciones morfológicas frecuentes en las infecciones por influenza. En las células ciliadas y no ciliadas del epitelio bronquiolar, se observan cuerpos de inclusión en el citoplasma asociados a degeneración celular; en las células no ciliadas se observa edema en la parte apical del citoplasma, retículo endoplásmico anormal y
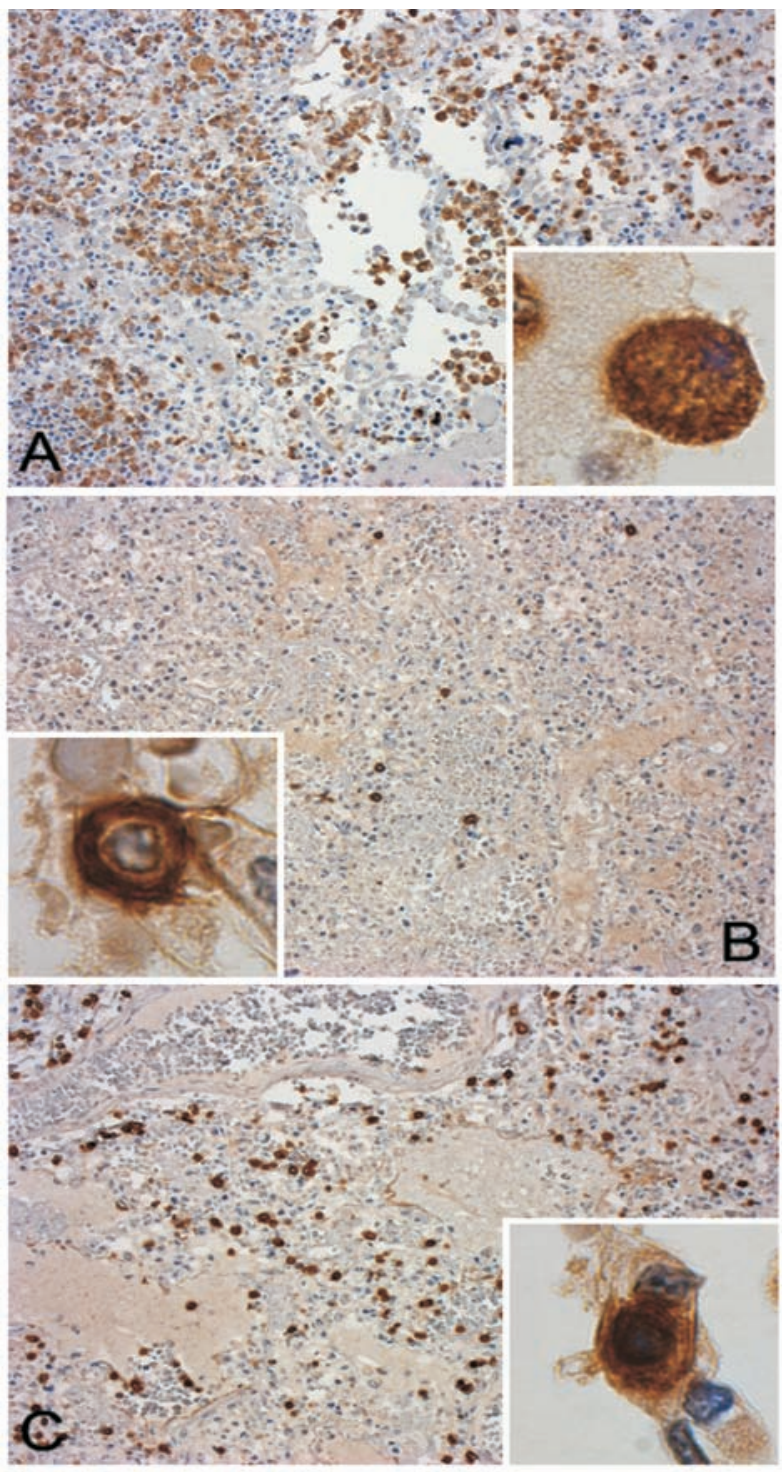

Figura 4. Infiltrado inflamatorio. A) Macrófagos alveolares e intersticiales, marcador CD68. B) Linfocitos B, marcador CD20. C) LinfocitosT, marcador CD3. (200X; inserto,1.600X).

replicación viral $(25,26)$. Además, se ha observado desprendimiento y fragmentación de la membrana en los neumocitos de tipo I, degeneración notable en neumocitos de tipo II con alteraciones intracelulares en mitocondrias y otros organelos, y vacuolas y glóbulos citoplásmicos (27).

La inmunorreacción de antígenos virales que se observa en los casos estudiados, principalmente en las células epiteliales bronquiolares, está asociada, probablemente, a la presencia de receptores de ácido siálico a-2,6 galactosa en este tipo celular. Se ha demostrado que estos receptores son reconocidos por la hemaglutinina de la partícula viral que media la formación del 
endosoma en la célula huésped (28,29); asimismo, algunos estudios han señalado que las células que presentan los receptores de unión al virus están localizadas predominantemente en el epitelio bronquiolar, y su cantidad es menor en el epitelio alveolar (30).

Taubenberger, et al. (2010), reportaron marcaciones para el antígeno en el epitelio pseudoestratificado del árbol traquebronquial y en el epitelio bronquiolar, en casos de autopsia (12). De forma similar, en los estudios con cerdos infectados naturalmente, se ha observado una fuerte inmunorreacción de antígenos virales en células del epitelio bronquiolar y bronquial, con menor marcación en el epitelio alveolar (31).

Los resultados del presente estudio, como los obtenidos por otros investigadores, sugieren que la principal zona de localización del antígeno viral es el epitelio bronquiolar, encontrándose una menor cantidad en áreas alveolares; sin embargo, teniendo en cuenta que los 20 casos estudiados presentaron una media de 8 días en el desarrollo de la infección entre el inicio de síntomas y el fallecimiento, es probable que la inmunorreacción baja en áreas alveolares, así como la ausencia de partículas virales ensambladas que no fueron observadas en el estudio mediante microscopía electrónica de transmisión, estén asociadas a títulos virales bajos en el tejido. Varios estudios en modelo de ratón han sugerido que los títulos virales en el desarrollo de la infección presentan un pico de replicación entre el primero y el segundo día después de la inoculación, observándose una disminución constante de los títulos hasta los días 7 y 8 , después de inducir la infección $(32,33)$.

En el presente estudio, los cambios morfológicos asociados a la infección viral en los casos de pacientes que fallecieron durante la pandemia de 2009 por influenza A H1N1/v09 en Colombia, permitieron confirmar algunas de las alteraciones pulmonares encontradas por otros estudios de la pandemia de 2009, así como en otros periodos pandémicos e interpandémicos. Sin embargo, a diferencia de los reportes previos, el bajo porcentaje de infección bacteriana concomitante es una característica sobresaliente que sugiere que la fatalidad de los casos estudiados, probablemente, no esté asociada a una enfermedad bacteriana secundaria. Además, la muerte podría estar relacionada con la insuficiencia respiratoria producida por las lesiones pulmonares descritas, como la neumonitis aguda exudativa fibrinoide y la alveolitis necrosante grave; asimismo, las complicaciones producidas por el edema pulmonar y la hemorragia intraalveolar contribuyeron en el resultado fatal.

Es probable que las lesiones observadas en este estudio se atribuyan al daño tisular en la respuesta inflamatoria celular y humoral asociada a la infiltración por células poliformonucleares y macrófagos en el intersticio y la luz alveolares, como también por la lesión viral.

Finalmente, los resultados obtenidos representan una aproximación al estudio básico de las alteraciones morfológicas asociadas a la infección por el virus respiratorio $\mathrm{AH} 1 \mathrm{~N} 1$ en casos del territorio colombiano y contribuye a resolver preguntas sobre una enfermedad, aunque ampliamente revisada, poco definida.

\section{Agradecimientos}

Al Instituto Nacional de Salud y a Colciencias y su programa de formación de Jóvenes Investigadores e Innovadores "Virginia Gutiérrez de Pineda" 20092010.

\section{Conflictos de Interés}

Los autores de este estudio declaramos que no existe ningún conflicto de interés.

\section{Financiación}

Este trabajo fue financiado por la Subdirección de Investigación del Instituto Nacional de Salud, Colciencias y su convenio de formación de Jóvenes Investigadores e innovadores año 20092010, convenio № 822/2009, y el Plan de Acción de la Subdirección Red Nacional de Laboratorios del Instituto Nacional de Salud.

\section{Referencias}

1. Verches P. Comportamiento de la pandemia por el nuevo virus de influenza AH1N1 en Colombia, a un año de detectarse el primer caso. Inf Quin Epidemiol Nac. 2010;15:241.

2. Michaelis $\mathbf{M}$, Doerr $\mathbf{H W}$, Cinatl $\mathbf{J} \mathbf{J r}$. An influenza $A$ $\mathrm{H} 1 \mathrm{~N} 1$ virus revival-pandemic $\mathrm{H} 1 \mathrm{N1} / 09$ virus. Infection. 2009;37:381-9.

3. Seth J, Robert M, Walter R, Gregory A. 2009 H1N1 influenza. Mayo Clin Proc. 2010;85:64-76.

4. Craighead J. Influenza viruses. En: Craighead J, editor. Pathology and pathogenesis of human viral disease. St Louis: Burlington Books; 2000. p. 35-46.

5. Ministerio de la Protección Social, Instituto Nacional de Salud. Boletín Epidemiológico Semanal. Semana epidemiológica número 18. Bogotá, D.C.: Ministerio de la Protección Social; 2010. 
6. Hinrichs S, Harrison C, Haggerty S. Viral Diseases. En: Damjanov I, Linder J, editors. Anderson's pathology..Tenth. edition. St Louis: Mosby Yearbook Inc.; 1996. p. 922-3.

7. Nicholson K, Wood J, Zambon M. Influenza. Lancet. 2003;362:1733-45.

8. Taubenberger J, Morens D. The pathology of influenza virus infections. Annu Rev Pathol. 2008;3:499-522.

9. Shieh W, Blau D, Denison A, Deleon-Carnes M, Adem P, Bhatnagar J, et al. 2009 pandemic influenza A (H1N1): Pathology and pathogenesis of 100 fatal cases in the United States. Am J Pathol. 2010;177:166-75.

10. World Health Organization. CDC protocol of real time RTPCR for swine influenza A (H1N1). Atlanta: WHO; 2009.

11. Nakajima N, Hata S, Sato Y, Tobiume M, Katano H, Kaneko $\mathrm{K}$, et al. The first autopsy case of pandemic influenza (A/ H1N1 pdm) virus infection in Japan: Detection of a high copy number of the virus in type II alveolar epithelial cells by pathological and virological examination. Jpn J Infect Dis. 2010;63:67-71.

12. Gill R, Sheng Z, Ely S, Guinee Jr D, Beasley M, Suh J, et al. Pulmonary pathology findings of fatal 2009 pandemic influenza $\mathrm{A} / \mathrm{H} 1 \mathrm{~N} 1$ viral infections. Arch Pathol Lab Med. 2010;134:235-43.

13. Mauad T, Hajjar L, Callegari G, da Silva L, Schout D, Galas F. Lung pathology in fatal novel human influenza A (H1N1) infection. Am J Respir Crit Care Med. 2010;181:72-9.

14. Soto-Abraham M, Soriano-Rosas J, Díaz-Quiñónez A, Silva-Pereyra J, Vázquez-Hernández $P$, Torres-López $\mathrm{O}$, et al. Pathological changes associated with the $2009 \mathrm{H} 1 \mathrm{~N} 1$ virus. N Engl J Med. 2009;361:2001-3.

15. Guarner J, Paddock C, Shieh W, Packard M, Patel M, Montague J, etal. Histopathologicand immunohistochemical features of fatal influenza virus infection in children during the 2003-2004 season. Clin Infect Dis. 2006;43:132-40.

16. Guarner J, Falcón-Escobedo R. Comparison of the pathology caused by $\mathrm{H} 1 \mathrm{~N} 1, \mathrm{H} 5 \mathrm{~N} 1$, and $\mathrm{H} 3 \mathrm{~N} 2$ influenza viruses. Arch Med Res. 2009;40:655-61.

17. Taubenberger J, Hultin J, Morens D. Discovery and characterization of the 1918 pandemic influenza virus in historical context. Antivir Ther. 2007;12:581-91.

18. Kash J, Tumpey T, Proll S, Carter V, Perwitasari O, Thomas M, et al. Genomic analysis of increased host immune and cell death responses induced by 1918 influenza virus. Nature. 2006;443:578-81.

19. Perrone L, Plowden J, García-Sastre A, Katz J, Tumpey T. H5N1 and 1918 pandemic influenza virus infection results in early and excessive infiltration of macrophages and neutrophils in the lungs of mice. PLoS Pathog. 2008;4:e1000115.
20. Peiris J, Hui K, Yen H. Host response to influenza virus: Protection versus immunopathology. Curr Opin Immunol. 2010;22:475-81.

21. Lee K, Rhim J, Kang J. Hyperactive immune cells (T cells) may be responsible for acute lung injury in influenza virus infections: A need for early immune-modulators for severe cases. Med Hypotheses. 2011;76:64-9.

22. Seo S, Hoffmann E, Webster R. Lethal H5N1 influenza viruses escape host anti-viral cytokine responses. Nat Med. 2002;8:950-4.

23. Chan M, Cheung C, Chui W, Tsao S, Nicholls J, Chan $\mathbf{Y}$, et al. Induction of pro-inflammatory cytokines in human macrophages by influenza $A(H 5 N 1)$ viruses: A mechanism for the unusual severity of human disease? Lancet. 2002;360:1831-7.

24. Lipatov A, Webster R. Factors determining the high pathogenicity of Hong Kong H5N1/97 influenza viruses in mammals. Inter Cong Series. 2004;1263:59-62.

25. Harford C, Hamlin A, Parker E. Electron microscopy of early citoplasmic changes due to influenza virus. J Exp Med. 1955;101:577-90.

26. Plummer M, Stone $\mathbf{M}$. The pathogenensis of viral influenzal pneumonia in mice. Am J Pathol. 1964;45:95-113.

27. Stinson S, Ryan D, Hardy J, Hwang-Kow S, Loosli C. Ephitelial and surfactant changes in influenza pulmonary lesions. Arch Pathol Lab Med. 1976;100:147-53.

28. Rogers G, Paulson J. Receptor determinants of human and animal influenza virus isolates: Differences in receptor specificity of the $\mathrm{H} 3$ hemaglutinin based on species of origin. Virology. 1983;127:361-73.

29. Gagneux P, Cheriyan M, Hurtado-Ziola N, van der Linden E, Anderson D, McClure $\mathrm{H}$, et al. Human-specific regulation of alpha 2-6-linked sialic acids. J Biol Chem. 2003;278:48245-50.

30. Nelli R, Kuchipudi S, White G, Perez B, Dunham S, Chang K. Comparative distribution of human and avian type sialic acid influenza receptors in the pig. BMC Vet Res. 2010;6:4

31. Jung T, Choi C, Chae C. Localization of swine influenza virus in naturally infected pigs. Vet Pathol. 2002;39:10-6.

32. Newby C, Rowe R, Pekosz A. Influenza A virus infection of primary differentiated airway epithelial cell cultures derived from Syrian golden hamsters. Virology. 2006;354:80-90.

33. Mori I, Komatsu T, Takeuchi K, Nakakuki K, Sudo M, Kimura Y. In vivo induction of apoptosis by influenza virus. J Gen Virol. 1995;76:2869-73. 